\title{
Oral and oropharyngeal impalement injury in pediatric patients- Focus on rural environment
}

\author{
Kabunda Syebele $^{\mathrm{a},{ }^{*}}$, Cornelia Van Straten ${ }^{\mathrm{b}}$, Lebaka Chidinyane ${ }^{\mathrm{a}}$ \\ a Department of Maxillo-Facial and Oral Surgery, University of Pretoria, South Africa \\ ${ }^{b}$ One Military Hospital, Department of Maxillo-Facial and Oral Surgery, Pretoria, South Africa \\ * Corresponding author at: Department of Maxillo-Facial and Oral Surgery, University of Pretoria, PO Box \\ 1266, Pretoria 0001, South Africa. Tel.: +27 123192551; fax: +27 123192172/123192173; mobile: +27 \\ 824144130. E-mail address: kabunda.syebele@up.ac.za (K. Syebele).
}

\begin{abstract}
Objective. This article describes a case series of oral and oropharyngeal impalement injuries in pediatric patients and highlights the peculiar etiological role of the rural environment.
\end{abstract}

Study design. The records of nine pediatric patients who presented with oropharyngeal impalement injuries were reviewed. The patients were all from various rural areas of South Africa. The article focuses on the challenges and risk of post-impalement injury infection in the context of a rural environment.

Results. There were eight boys and one girl. The ages of the study participants ranged from two to ten years. Object-to-head injury was the predominant etiopathogenic mechanism (six cases) compared with head-to-object injury (three cases). Six out of nine lesions were shallow. The hard palate was the single most commonly affected site. Two cases (2/9) of post-impalement injury infection were recorded.

Conclusion. Although the risk of infection post-oropharyngeal impalement injury is reported to be low, it remains, however, a legitimate concern in cases occurring in the rural environment. The specific challenges in terms of health infrastructures in the rural 
environment, especially in developing countries, may have an impact on the ways oropharyngeal impalement injuries are managed.

\section{Introduction}

Impalement injuries of the oral cavity and the oropharynx structures are common among the pediatric population. Several well-documented cases of impalement injury have been reported. $^{1-10}$

The clinical presentation in most reported cases usually consisted of only a few symptoms. ${ }^{3-7}$ The entrance wound was small with no active bleeding in the majority of cases. This clinical picture of "mild trauma" on an otherwise stable patient might in some cases mislead parents and health care providers towards initial under-diagnosis and under-estimation of the possibility of serious, delayed complications. There are reports in the literature of well-documented cases of fatal outcomes after impalement injuries. ${ }^{10,14,15}$ The concept of the "lucid interval" between the time of the accident and the onset of vascular or neurological complications must always be borne in mind. However, the majority of intraoral impalement injuries were successfully treated with minimal surgery and healed without major sequelae. , 3-10 $^{-10}$

A variety of injuring objects have been described in the literature. ${ }^{1,4,8,13}$ In general, many other objects, sharp or blunt, may create trauma to the oral cavity and its surrounding soft-tissue structures (Fig. 1).

In this article, we present a case series of penetrating injuries to the oral cavity and the oropharynx, in a group of pediatric patients. The article describes the specific etiological scenarios of oropharyngeal penetrating injuries as they may be encountered in the rural 


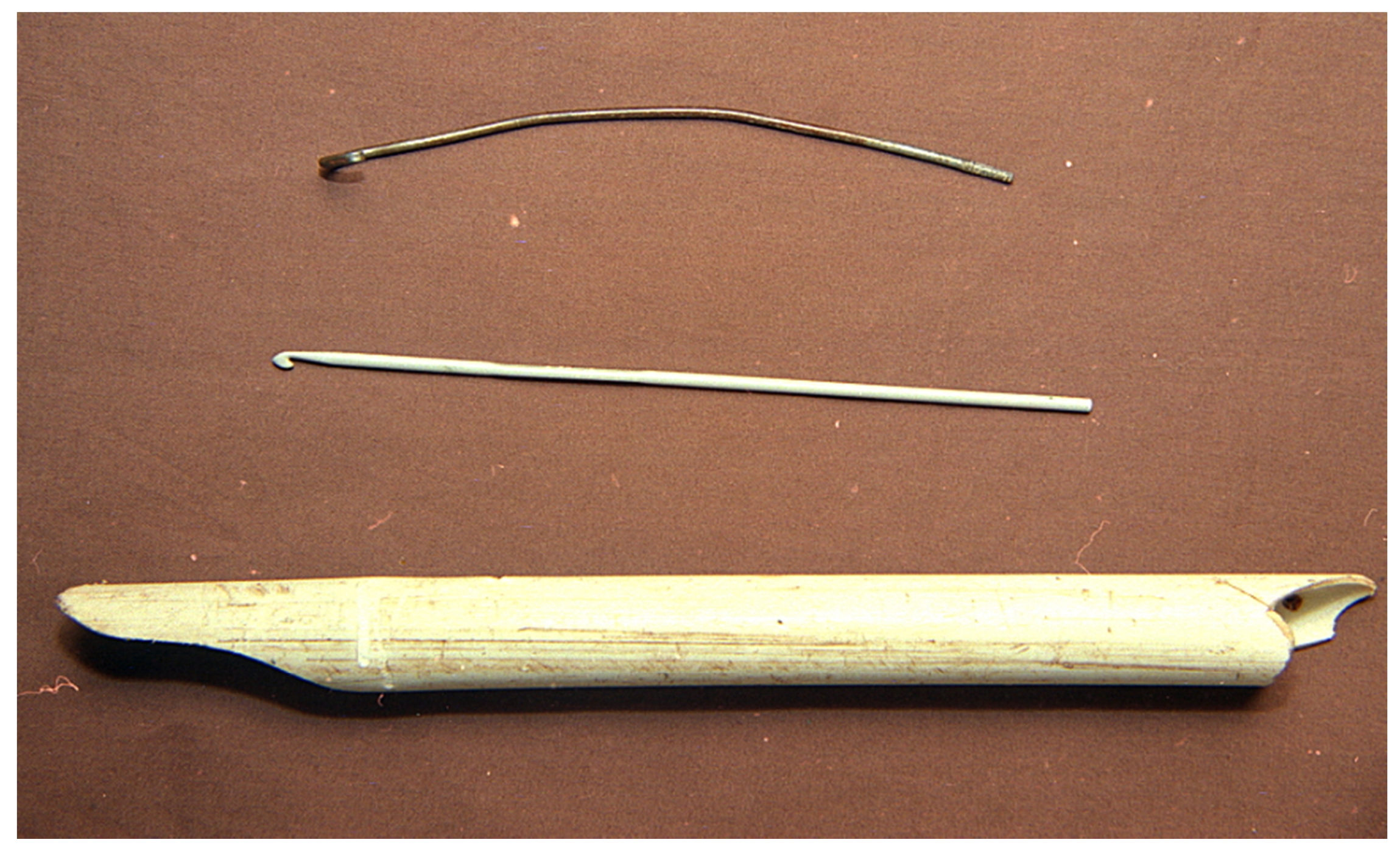

Fig. 1. A set of injuring objects as they may be encountered in the rural environment. 
environment. The treatment challenges and the risk of infection as a possible complication are highlighted.

\section{Patients and methods}

The files of nine patients from rural areas in the Republic of South African were retrospectively reviewed (Table 1). Different injuring objects are listed with their relationship to infection as a complication.

Three specific cases were selected and described in detail. These cases summarize the majority of clinical features and associated challenges that may be encountered.

Table 1. Socio-epidemiological data and clinical results for nine pediatric patients.

\begin{tabular}{|c|c|c|c|c|c|c|c|}
\hline $\begin{array}{l}\text { Case } \\
\text { No. }\end{array}$ & Sex & Age & $\begin{array}{c}\text { Injuring } \\
\text { object }\end{array}$ & Injury location & $\begin{array}{l}\text { Etiopathogenic } \\
\text { mechanism }\end{array}$ & Infection & $\begin{array}{l}\text { Depth of the } \\
\text { injury }\end{array}$ \\
\hline 1 & M & 10 & $\begin{array}{l}\text { Rusted steel } \\
\text { wire }\end{array}$ & $\begin{array}{l}\text { Parapharyngeal (from } \\
\text { retro molar area) }\end{array}$ & Head-to-object & No & Deep \\
\hline 2 & $\mathrm{M}$ & 10 & $\begin{array}{l}\text { Wooden } \\
\text { stick }\end{array}$ & Cheek & Head-to-object & Yes & Deep \\
\hline 3 & $\mathrm{~F}$ & 6 & $\begin{array}{l}\text { Knitting } \\
\text { crochet }\end{array}$ & Cheek & Object-to-head & No & Shallow \\
\hline 4 & $\mathrm{M}$ & 6 & $\begin{array}{l}\text { Wooden } \\
\text { stick }\end{array}$ & Cheek & Head-to-object & Yes & Shallow \\
\hline 5 & M & 5 & $\begin{array}{l}\text { Metallic } \\
\text { object }\end{array}$ & Hard palate & Object-to-head & No & Shallow \\
\hline 6 & $\mathrm{M}$ & 5.5 & $\begin{array}{l}\text { Metallic } \\
\text { object }\end{array}$ & Hard palate & Object-to-head & No & Shallow \\
\hline 7 & M & 2 & $\begin{array}{l}\text { Metallic } \\
\text { object }\end{array}$ & Hard palate & Object-to-head & No & Shallow \\
\hline 8 & M & 7 & $\begin{array}{l}\text { Cylindric } \\
\text { PVC tube }\end{array}$ & Hard palate & Object-to-head & No & Shallow \\
\hline 9 & M & 7 & Vuvuzela ${ }^{\mathrm{a}}$ & Soft palate & Object-to-head & No & $\begin{array}{l}\text { Deep } \\
\text { (perforating) }\end{array}$ \\
\hline
\end{tabular}

Noisy blowing plastic trumpet used during the 2010 world soccer tournament in South Africa. 


\section{Case No. 1}

A ten-year-old boy was referred to the dental clinic for evaluation and management after a steel wire had traumatically intruded through his mouth. The incident took place some hours before the consultation. The boy had fallen down with his mouth open during a soccer game in a rural and dusty soccer field. He then stood up with a piece of steel wire protruding out of his mouth. The attempts made to blindly pull out the piece of wire by friends, parents, and the general practitioner initially consulted were unsuccessful.

Upon clinical examination, the family and the young patient were anxious. The only positive feature of the extra-oral examination was a piece of rusty steel wire extruding from the mouth. Intra-orally, the same steel wire could be observed penetrating the oropharynx, medially to the retro-molar area, approximately $1 \mathrm{~cm}$ above the occlusal plane. There was no active bleeding noted. The penetrating wound displayed a dilacerated and erhythematous margin around the wire.

The main radiographic finding in both the frontal and lateral views was that the tip of the wire was unexpectedly hooked (Fig. 2). These basic radiographs show the wire lying parallel to the ramus, deep in the pterigo-mandibular space.

A meticulous dissection around the wire permitted its extraction under local anesthesia, without damage to any valuable vascular structure. The wound was generously irrigated with normal saline solution and left open (unsutured). General measures (tetanus toxoid, antibiotics, and NSAI drugs) were also prescribed. The postoperative period was uneventful. 


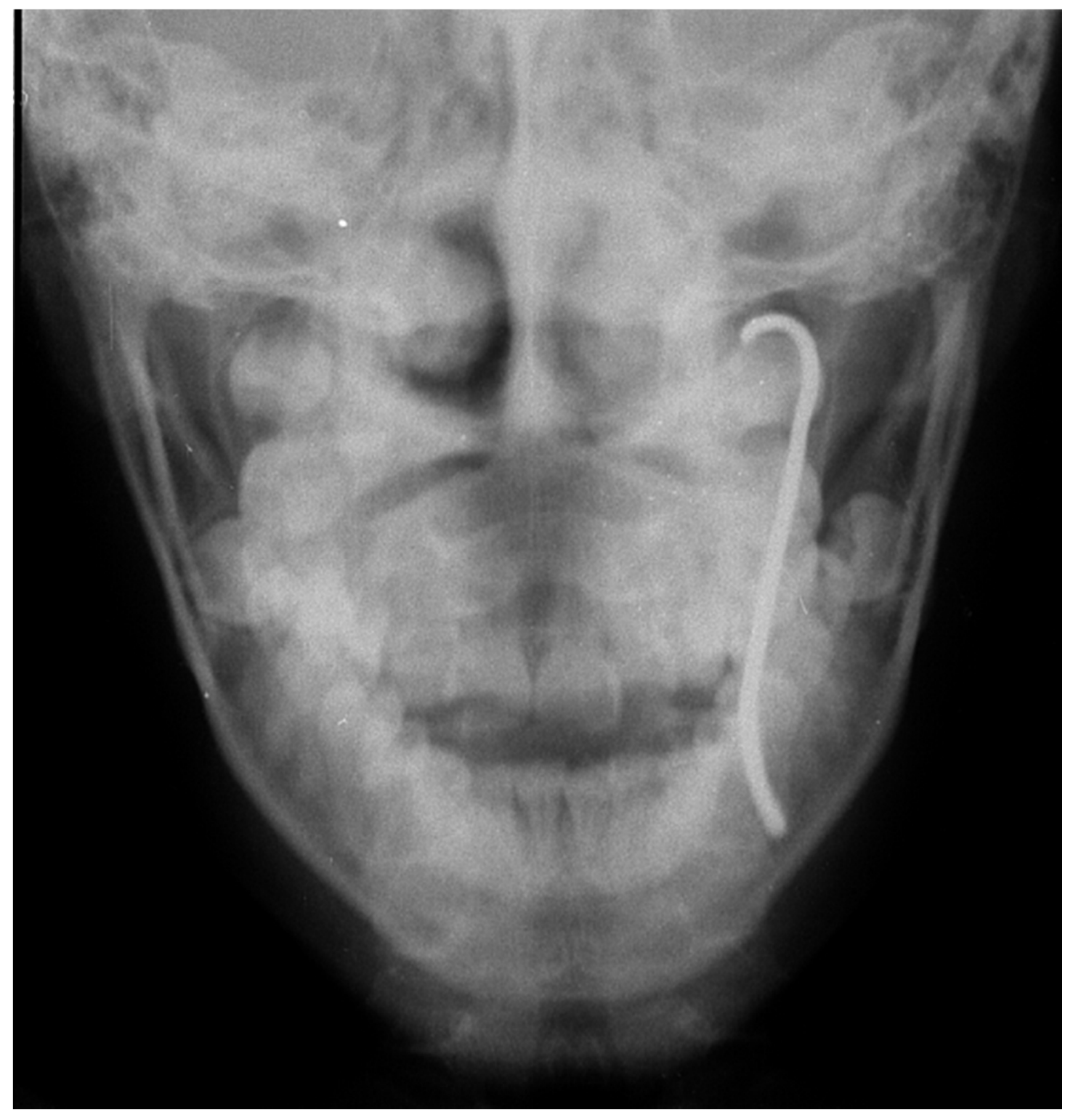

Fig. 2A. Frontal view of plain radiographs, showing a steel wire with its hooked tip in case No: 1. 


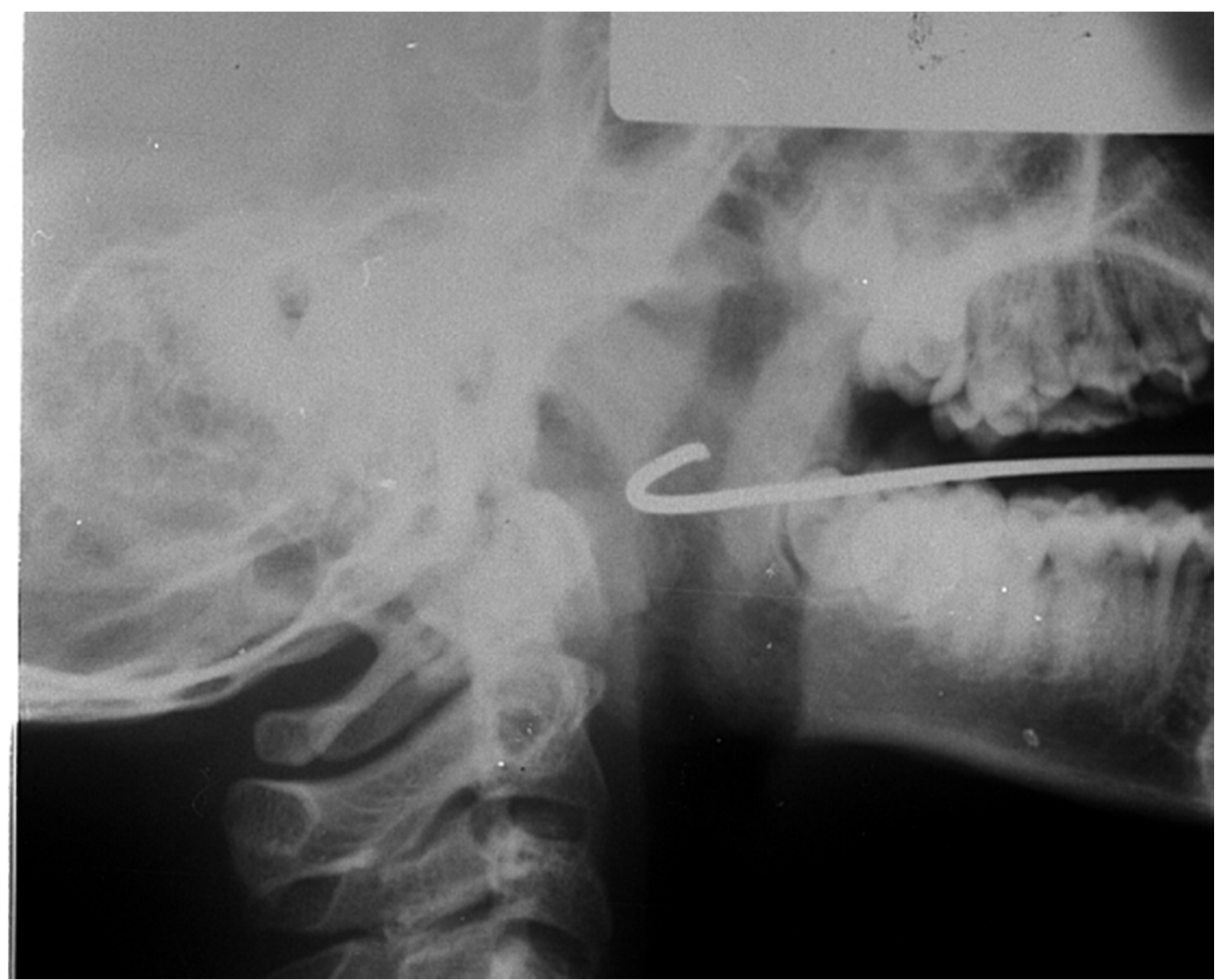

Fig. 2B. Lateral view of plain radiographs, showing a steel wire with its hooked tip in case No: 1. 


\section{Case No. 2}

A 10-year-old boy was referred to the dental clinic for the further management of a nonhealing "abscess" in the mouth. The patient also complained of a foreign-body sensation in the left cheek. The boy mentioned that he had fallen down a week ago on a sharp wooden stick with his mouth open. The incident happened while he was collecting firewood in the bush. He was initially assisted on the scene by his friends, who managed to pull a piece of the wooden stick out from his mouth.

The physical examination revealed a fistula with purulent discharge in the left buccal aspect, approximately $1.5 \mathrm{~cm}$ above the occlusal plane, lateral to the anterior margin of the ramus of the mandible. Upon exploration of the fistula with a probe, a loose and hard object was detected. The standard radiographs (frontal and lateral views) were unremarkable. A diagnosis of foreign-body retention after an impalement accident was made.

The patient was treated under local anesthesia. A small piece of wood was removed through the pre-existing fistula, and the wound was once again generously cleansed and left open. General measures were prescribed, and the patient was observed to have recovered remarkably well a few days later.

\section{Case No. 3}

A seven-year-old boy was referred from a remote area of South Africa to the outpatient unit of Maxillo-Facial and Oral Surgery. The reason for the referral was the management of a wound in the soft palate. The medical history mentioned that the boy had fallen down a day before, while playing with a plastic trumpet "Vuvuzela" in his mouth (Fig. 3) The physical examination revealed the presence of a penetrating (through-and- through) 


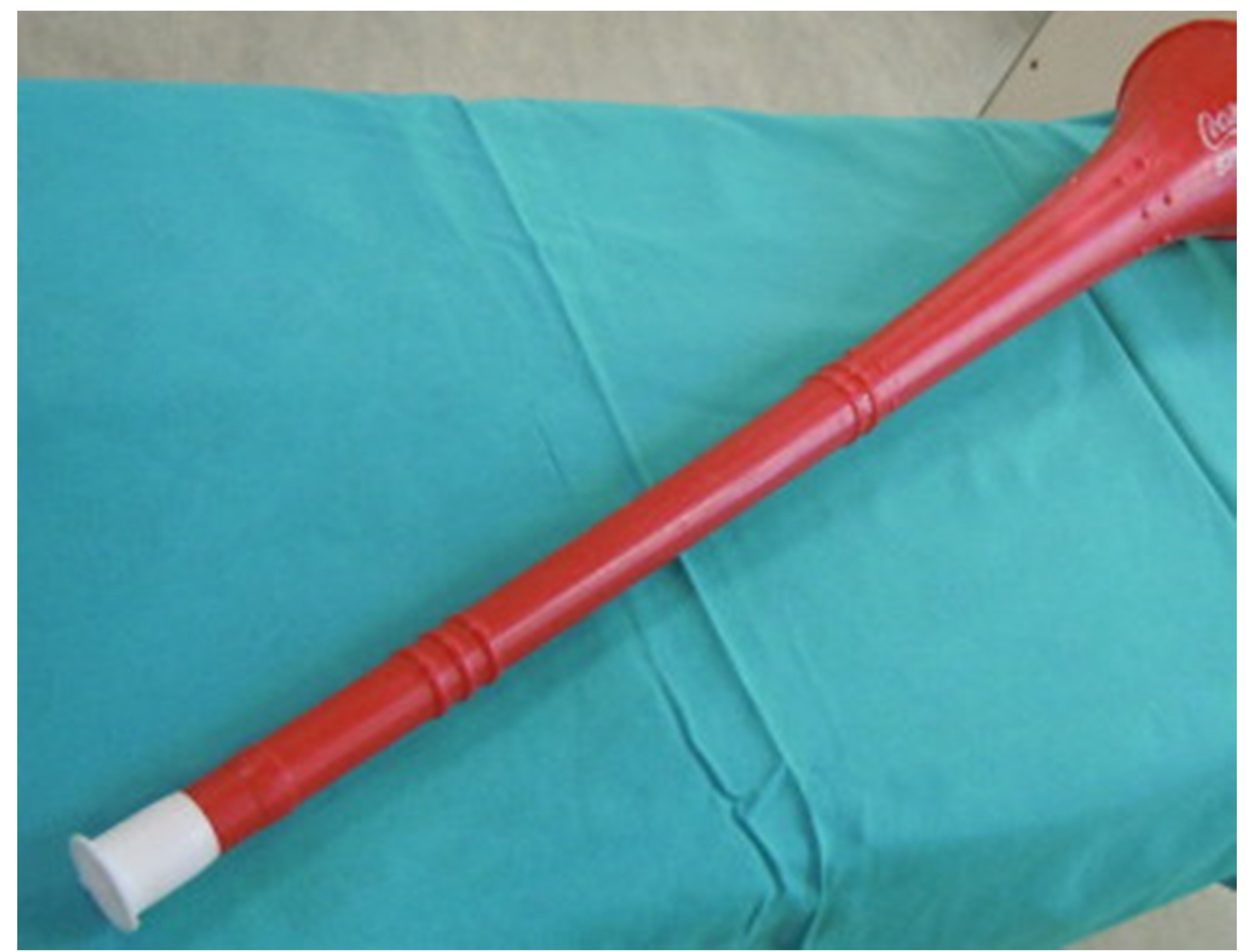

Fig. 3. A plastic trumpet called "Vuvuzela". A blunt object that could still create a severe laceration of the soft palate as seen in Fig. 4. 
laceration in the left soft palate (Fig. 4). No active bleeding was noted, and the patient was calm. The treatment consisted of a multi-layer surgical repair (Fig. 5), which was performed under general anesthesia. Postoperative healing was uneventful.

\section{Results}

The epidemiological and clinical data for nine patients are presented in table 1 . The ages of patients ranged from two to ten years, and the majority were boys (eight out of nine). The etiological agent tended to be dirty metallic objects, followed by wooden sticks and plastic materials. The palate was the most common site of injury. The majority of injuries were superficial with a depth of less than $1 \mathrm{~cm}$. However, two blunt injuring objects created deeper ( $>1 \mathrm{~cm}$ of depth) and severe through and through injuries: the steel wire and the Vuvuzela (Fig. 2 and 3). No neurological complications were reported. The two patients injured by wooden stick both presented partial retention of the wooden stick, which was initially ignored and subsequently provoked secondary wound infection.

\section{Discussion}

A survey of the pediatric literature revealed a substantial number of publications on oropharyngeal impalement injuries in young patients. ${ }^{1-10}$ From the epidemiological perspective, the injury is predominantly found in pediatric patients who are less than 10 years and affects boys more often than girls. ${ }^{1,8}$ This article concurs with these findings. Two main etiopathogenic mechanisms may be considered. The first is the instance where the traumatic object (sharp or blunt) is carried in the mouth of the patient and is forcefully pushed back toward the oropharynx by a sudden stop or impact (object-to-head). Such 


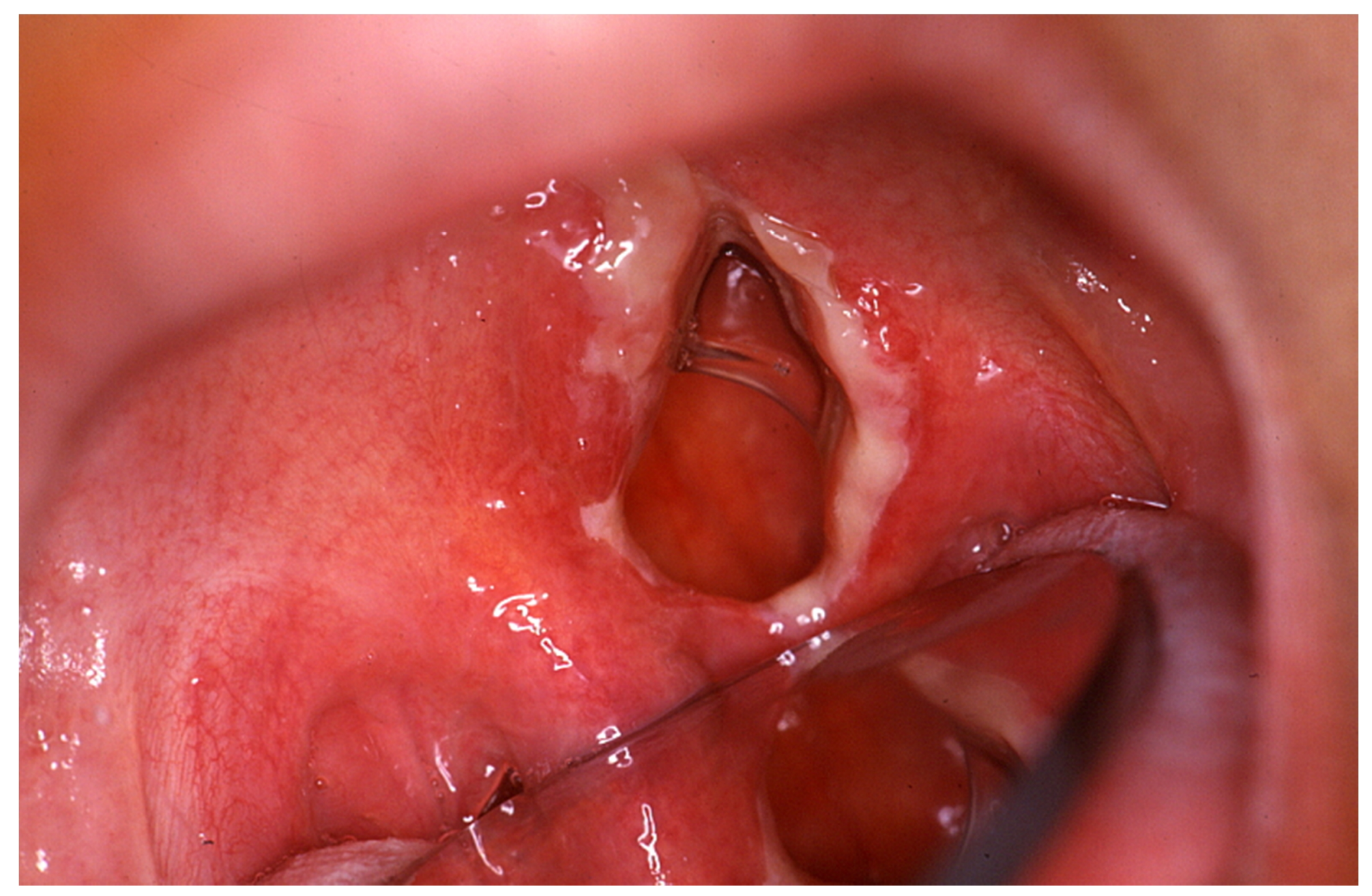

Fig. 4. This through-and-through laceration of the soft palate has been caused by a "Vuvuzela". 


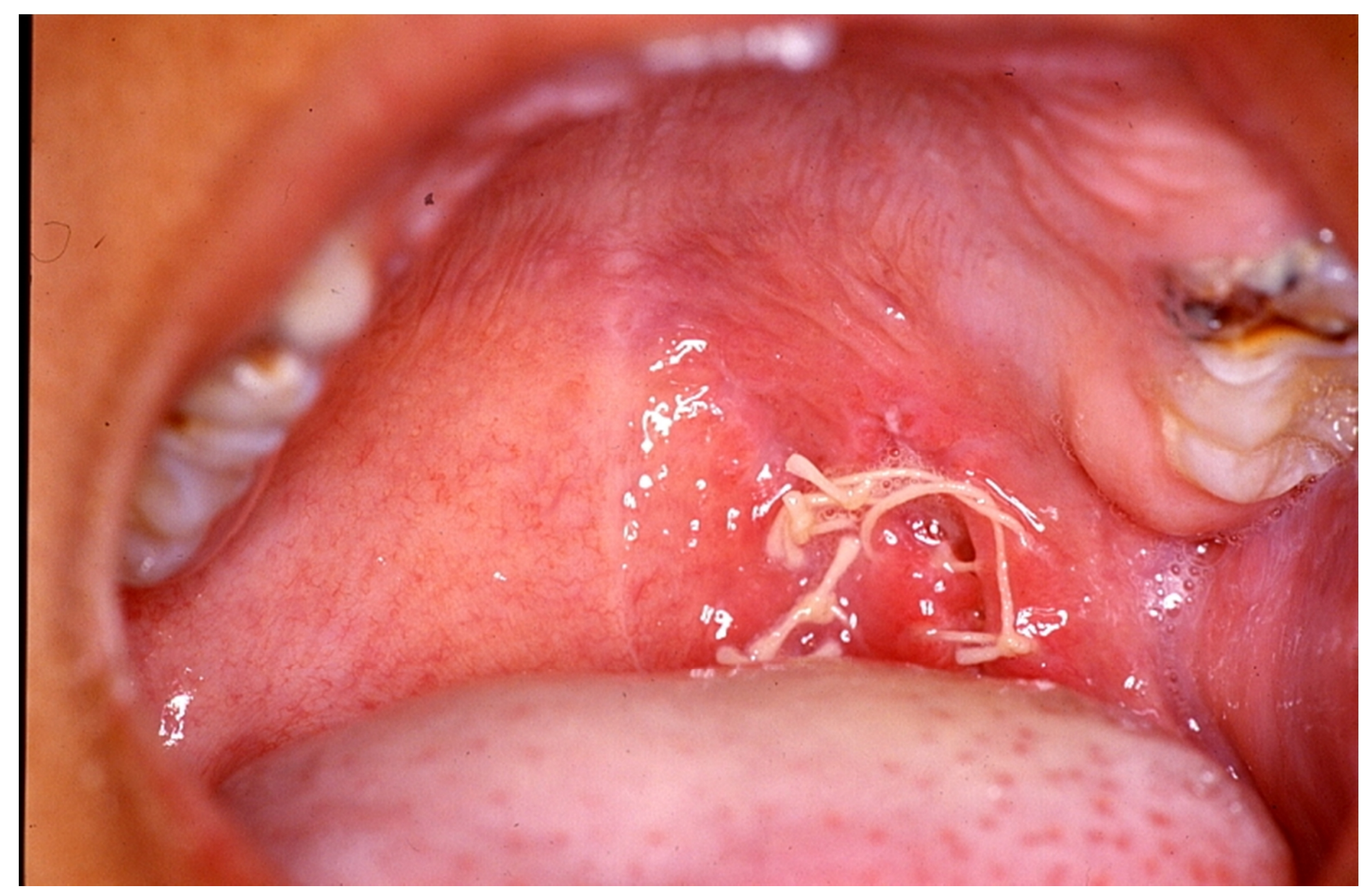

Fig. 5. The same laceration as in Fig. 4, after multilayers surgical repair. 
incidents commonly occur indoors and occur when a child falls or hits any obstacle with an object held in his/her mouth, for example. The second mechanism involves the child falling down toward a fixed object with his / her mouth open (head-to-object). Such incidents may happen during games in unsafe playgrounds as it may be observed in rural areas. In the latter circumstances there is, therefore, a higher probability that the object might be soiled. The possibility of contamination by general microorganism or more dangerously the possibility of tetanus infection is not excluded. The results in Table 1 show that the traumatic object in all head-to-object cases was made of deeply soiled material (rusted wire or wood). These types of incidents occur more often in outdoor environment and represent true accidents that are difficult to prevent.

The rate of infection as complication post-impalement injury is reported to be quite low. Hennelly et al. ${ }^{1}$ reported $1.4 \%$ ( 3 out of 205 audited cases) of infection. This article reports two out of nine cases of infection post-impalement injury. They both relate to head-to-object mechanisms of injury with the wooden stick as the injuring object. They also shared the retention of the foreign body post impalement injury, leading to the subsequent infection. Notwithstanding the limitations of the small sample, these results suggest that the risk of post impalement infection in cases occurring in the rural environment must always be considered. The initially undiagnosed retention of the injuring object may play a role as determining factor in the subsequent advent of chronic infection. $^{11}$

The clinical presentation differs depending on whether the injuring object has been removed before the consultation. It is easier to clinically appreciate the gravity of the situation in fresh cases, when the injuring object is still hanging from the mouth. This 
allows the caregiver to be able to identify the nature of the traumatic object, i.e., a toothbrush, and react accordingly. However, the situation is completely different in cases where the traumatic object has been removed prior to the consultation. The absence of active bleeding and the general lack of any other life-threatening factor always mislead both parents and general practitioners. The majority of cases are under-diagnosed, and people often assume that the entire object has been removed. Some parts of the object might not be detected clinically with standard radiography. Plastic pen caps or pieces of a wooden stick may remain entrapped in the oropharyngeal soft-tissue spaces and provoke secondary infection and trismus. ${ }^{4,11}$ Other severe and delayed complications may occur in some rare cases. Neurological deficits, stroke, profuse delayed hemorrhage, and internal carotid artery thrombosis are some of the complications that have been reported. ${ }^{12-15}$ The minute possibility that these rare and delayed complications may occur is the basis of the on-going debate about the need for special investigations, as well as the need for hospital observation for at least 24 hours. ${ }^{10,15}$ No neurological complication has been observed in the current reported series of patients. However, in the specific context of the rural environment, the issue of whether to pursue hospital observation for 24 to 72 hours remains relevant. The access to emergency and specialized medical services is not always readily available when needed. ${ }^{15}$ We also believe that it is unrealistic to rely on the family in the rural area to monitor the patient for the development of neurovascular symptoms. Some families may not be able to read and understand the instructions (technical terms). The lack of information is a major handicap. Therefore, it would not be, from managerial perspective, a misuse of resources to observe the young patient in the hospital for a short period as needed. 
It is generally reported that the rate of complete recovery post oropharyngeal impalement injuries is high. Therefore, the need for systematic request of sophisticated special investigations such as CT scan, MRI, angiography, Doppler is minimal. ${ }^{1,8}$, More often, the clinical presentation is that of mild injury, without any threat to the life of the patient, and it can be managed with minimal intervention. Nevertheless, it remains in the best interest of the patient that such investigations are performed in case of any doubt. The risk of rare but still serious neurological and vascular complications needs to be eliminated with certainty. Adoga et al. ${ }^{15}$, report a case of impalement injury with fatal out-come. A computerized tomography angiogram, which could not be done, could have probably been of great help in managing the case. This sad incident illustrates the type of challenges that may be experienced in rural environment. The authors' point of view is that the selection of cases and the type of special investigations to be requested should be based on the merit of each specific case. The accurate recording of the medical history, coupled with a meticulous physical examination, remain of utmost importance and should allow the clinician to make an informed decision. However, the main challenge remains the difficult balance between the cost/benefit ratio of the special investigations, and the possibility of any lawsuit in the case of any undetected, delayed complication.

In this article we also stress the importance of not attempting to blindly pull out the injuring object. This approach by whoever is the first on the scene (friends, parents or general practitioner) remains dangerous. Information regarding the configuration and the exact location of the object in relation to vital cervical vessels might be lacking at this initial stage (Fig. 2A and 2B) $)^{11,15}$. This practice also increases the probability of leaving a part of the injuring object in the body. Wooden sticks are likely to break apart, leaving a 
piece behind. Parts of plastic pens have been reported to remain lodged in the cervical and parapharyngeal soft tissues for long periods of time. ${ }^{4,11}$

The management of the entrance wound deserves special attention. In the majority of cases the entrance to the penetrating injury is a small laceration. In some publications, the wound is sutured, irrespective of the nature of the traumatic object, and sometimes irrespective of the time that has elapsed between the occurrence of the incident and the time of treatment. ${ }^{3-5,7}$ This article highlights the heavily soiled nature of the traumatic objects (rusted steel wire, wooden stick) encountered in the rural environment. Therefore, the present authors suggest that it is good practice to generously irrigate the penetrating wound with normal saline solution and then to leave it open (unsutured). ${ }^{9,10}$

However, the treatment of specific cases of hard- or soft-palate injury merits special consideration. A large hanging flap of hard palate must be repositioned and sutured. A laceration through the palate also requires multi-layer surgical repair (Fig. 4 and 5). The aim of this latter approach is to prevent any possibility of post-traumatic or postoperative fistula in the palate, which may later impact on the child's speech ability.

\section{Conclusion}

The majority of authors recommend parental supervision as a means of preventing oropharyngeal impalement injuries in pediatric patients. This is conceivable in the urban context, which is associated with a lot of time spent indoors. Indeed, the child should be prevented from carrying any possible injuring object in the mouth while playing by the supervising adult. 
However, the situation is completely different in the rural environment. The child in the majority of cases does not have control over the timing and place of the accident. The young patient does not have control over the nature of the injuring object either. These types of incidents typically occur in the outdoor environment and represent true accidents that are difficult to prevent.

The risk of infection post-oropharyngeal impalement injuries, although reportedly low, remains a real concern in the rural environment, due to the soiled nature of the injuring object.

\section{References}

1. Hennelly K, Kimia A, Lee L, Jones D, Porter SC. Incidence of morbidity from penetrating palate trauma. Pediatrics2010;126;e1578;DOI:10.1.542/PEDS.2010-1059.

2. Kupietzky A. Clinical guidelines for the treatment of impalement injuries of the oropharyn in children. Pediatr Dent. 2000;22:229-231.

3. Tanaka T, Sudo M, Iwai K, Fujieda S, Saito H. Penetrating injury to the pharynx by a toothbrush in a pediatric patient: a case report. Auris Nasus Larynx. 2002;29:387-389.

4. Patel N, McVeigh K, Sharma P, Parmer S. An impalement injury to the oropharynx in a paediatric patient - a case report. Brit J Oral Max Surg. 2011;49:e12-s13.

5. Jounessi OJ, Alcaino EA. Impalement injuries of the oral cavity in children: A case report and survey of the literature. Int J paediatr Dent. 2007;17:66-71.

6. Belfer RA, Ochsenschlager DW, Tomaski SM. Penetrating injury to the oral cavity: A case report and review of the literature. J Emerg Med. 1995;13:331-335. 
7. Lalitha RM, Ramganath K, Prasad K, Agrawal K, Perumal M. Potential danger of toothbrushes for children. J Invest Clin Dent. 2011;2:148-150.

8. Hellmann JR, Shott SR, Gootee MJ. Impalement injuries of the palate in children: review of 131 cases. Int J Pediatr Otorhinolaryngol. 1993;26:157-163.

9. Matsusue Y, Yamamoto K, Horita S, Inagake K, Kirita T. Impalement injuries of the oral cavity in children. J Oral Maxillofac Surg. 2011;69:e147-e151.

10. Randall DA, Kang R. Current management of penetrating injuries of the soft palate. Otolaryngol Head Neck Surg. 2006;135:356-360.

11.Kandi K, Sabwe M, Matulewicz S, Dimfuana S, Syebele K. Importance of clinical observation in evaluation of a partially opaque foreign body impacted in the interstylomastoid region. Odontostomatol Trop. 1986;4:209-212

12. Melio FR, Jones JL, Djang WT. Internal carotid artery thrombosis in a child secondary to intraoral trauma. J Emerg Med. 1996;14:429-433.

13. Caldwell J. Postraumatic thrombosis of internal carotid artery. Am J Surg. $1956 ; 32: 522-523$.

14. Caldwell J. Thrombosis of internal carotid artery in childhood after injuries in region of soft palate. Br Med j. 1956;1:665-666.

15. Adoga AA, Sandabe MB, Bemu A, Musa E, Bakari AA, Kodiya AM, Ahmad BM. Impalement injury of the oro-pharynx with fatal consequences in a child: A case report and review of the literature. Medical Case Studies. 2011;2:39-43. Available online at http://www.academiccjournals.org/MCS ISSN2141-6532 @2011 Academic Journals. 